\title{
Cardiopulmonary resuscitation traumatic cardiac arrest - there are survivors.An analysis of two national emergency registries
}

Jan-Thorsten Gräsner ${ }^{1 *}$, Jan Wnent ${ }^{2}$, Stephan Seewald ${ }^{1}$, Patrick Meybohm¹, Matthias Fischer ${ }^{3}$, Thomas Paffrath ${ }^{4}$, Arasch Wafaisade ${ }^{4}$, Berthold Bein ${ }^{1}$ and Rolf Lefering ${ }^{5}$, for German Resuscitation Registry Working Group, Trauma Registry of the German Society for Trauma Surgery (DGU)

\begin{abstract}
Introduction: Cardiac arrest following trauma occurs infrequently compared with cardiac aetiology. Within the German Resuscitation Registry a traumatic cause is documented in about 3\% of cardiac arrest patients. Regarding the national Trauma Registry, only a few of these trauma patients with cardiac arrest survive. The aim of the present study was to analyze the outcome of cardiopulmonary resuscitation (CPR) after traumatic cardiac arrest by combining data from two different large national registries in Germany.
\end{abstract}

Methods: This study includes 368 trauma patients (2.8\%) out of 13,329 cardiac arrest patients registered within the Resuscitation Registry, whereby 3,673 patients with a cardiac cause and successful CPR served as a cardiac control group. We further analyzed a second group of 1,535 trauma patients with cardiac arrest and early CPR registered within the Trauma Registry, whereby a total of 25,366 trauma patients without any CPR attempts served as a trauma control group. The relative frequencies from each database were used to calculate relative percentages for patients with traumatic cardiac arrest in whom resuscitation was attempted.

Results: Within the Resuscitation Registry, cardiac arrest was present in 331 patients (89.9\%) when the EMS personal arrived at the scene and in 37 patients (10.1\%) when cardiac arrest occurred after arrival. Spontaneous circulation could be achieved in 107 patients (29.1\%). A total of 101 (27.4\%) were transferred to hospital, 95 of whom (25.8\%) had return of spontaneous circulation (ROSC) on admission. According to the Trauma Registry, the overall hospital mortality rate for cardiac arrest patients following trauma was $73 \%$ ( $n=593$ of 814). About half of the patients who were admitted alive to hospital died within 24 hours, resulting in 13\% survivors within 24 hours. $7 \%$ of the patients survived until hospital discharge, and only $2 \%$ of the patients had good neurological outcome.

Conclusions: Our present study encourages CPR attempts in cardiac arrest patients following severe trauma. When a manageable number of patients is present, the decision on whether to start CPR or not should be done liberally, using comparable criteria as in patients with cardiac etiology. In this respect, trauma management programs that restrict CPR attempts should not be encouraged.

\section{Introduction}

Cardiac arrest following trauma occurs relatively rarely in comparison with cardiac or other etiologies. Within the German Resuscitation Registry (GRR) that is managed by the German Society of Anaesthesiology and

\footnotetext{
* Correspondence: graesner@anaesthesie.uni-kiel.de

'Department of Anaesthesiology and Intensive Care Medicine, University Hospital Schleswig-Holstein, Campus Kiel, Schwanenweg 21, Kiel, 24105, Germany

Full list of author information is available at the end of the article
}

Intensive Care Medicine (Deutsche Gesellschaft für Anästhesiologie und Intensivmedizin, DGAI), traumatic cause is documented in about $3 \%$ of cardiac arrest patients [1].

Pre-hospital cardiopulmonary resuscitation (CPR) is performed infrequently in patients with severe trauma. The Trauma Registry of the German Society for Trauma Surgery (Deutsche Gesellschaft für Unfallchirurgie, TRDGU) registers patients who had severe injuries with a 
potential need for intensive care and who had spontaneous circulation on admission. Approximately $3 \%$ of these severely injured patients documented within the TR-DGU received CPR attempts outside the hospital. Only a few of these patients survived [2], and only 1 out of 10 patients with pre-hospital CPR attempts achieved a good outcome [3].

There is an ongoing debate in terms of the effectiveness of CPR in trauma patients, particularly with regard to good long-term outcomes [4-6]. International trauma training courses have even suggested that no intervention should be started in cardiac arrest patients with primary asystole due to traumatic causes [3].

Several factors are known to influence the success of CPR. The most important factor is time. If cardiac arrest occurs during pre-hospital treatment and is observed by an emergency physician, intervention and transport should be started without any delay. Other pre-hospital factors influencing the primary goal of CPR - the return of spontaneous circulation (ROSC) have recently been analyzed and identified within the GRR [7]. General prognostic factors known to influence survival after trauma, such as age, blood loss, and the severity of injury, also affect this subgroup of trauma patients.

Since the TR-DGU, however, is limited to trauma patients who had spontaneous circulation at hospital admission, we now combine data from two different large national registries mentioned above - the GRR and the TR-DGU - to analyze the success rate of CPR after traumatic cardiac arrest in Germany.

Design and publication of this study were approved by the scientific committee of the GRR and the TR-DGU in compliance with current publication guidelines. This study was approved by the ethics committee of the University of Cologne, Faculty of Medicine (Kerpener Str. 62, 50937 Cologne, Germany) (Register Number 11-014) and the ethics committee of the University of Kiel, Faculty of Medicine (Schwanenweg 20,24105 Kiel, Germany) (Register Number D456/11).

\section{Materials and methods}

\section{German Resuscitation Registry (GRR)}

The GRR currently represents 51 emergency medical systems that record data on out-of-hospital CPR attempts throughout the country, covering a population of nine million citizens (the total population of Germany is 85 million). Participation is voluntary. In Germany, emergency medical systems (EMS) are staffed by emergency physicians from several medical specialties (mainly anesthesiology, surgery, and internal medicine) who had additional training in emergency medicine. The registry is organized and funded by the DGAI [8].
The GRR is divided into two different data sets. Firstly, a 'preclinical care' data set derived from the Utstein-style template for uniform reporting of cardiac arrest, aiming at documentation of pre-hospital logistic issues, presumed aetiology, resuscitation therapy and the patient's initial outcome, including 118 variables. Secondly, the 'post-resuscitation care' data set is aimed at documenting in-hospital post-resuscitation efforts. Due to the anonymity of data collection and the fact that the primary purpose of the GRR is quality control, patient consent was not necessary [1]. ROSC was defined as a palpable pulse for more than 20 seconds $[9,10]$. Admission to hospital (ATH) was regarded as a positive outcome if circulation was still present on hospital admission (group $\mathrm{A}_{\mathrm{GRR}}$ ). Failure of pre-hospital ROSC or ongoing CPR on admission was defined as a negative outcome (no ROSC/no ATH; group B).

Within the GRR 13,329 out-of-hospital cardiac arrest patients were prospectively documented between 1998 and 2010 for which a professional pre-hospital EMS team was requested by dispatchers. The present study includes 368 patients (2.8\%) with cardiac arrest most probably due to traumatic cause; 3673 cardiac arrest patients with a cardiac cause and with ROSC at hospital admission served as a 'cardiac control group' (group C).

Patients from the GRR were divided into the following three groups:

- group $\mathrm{A}_{\mathrm{GRR}}$ : pre-hospital CPR with ATH $(n=95)$

- group B: pre-hospital CPR without ROSC/ATH $(n=$ 273)

- group C: cardiac control group with ROSC $(n=$ 3,673).

\section{Trauma Registry of the German Society for Trauma Surgery (TR-DGU)}

The TR-DGU is a prospective structured database established in 1993. Participation has been voluntary until recently, when it became an obligatory tool for quality assessment in regional trauma networks [11]. Data from the pre-hospital phase, early in-hospital phase (emergency department), ICU and hospital care until discharge from hospital are collected in an anonymous fashion. Patients who had severe injuries with a potential need for intensive care and who had spontaneous circulation on admission, were included. In contrast to the GRR, patients with burns, drowning, poisoning and preclinical deaths were excluded. Data were documented within the TR-DGU via a password-protected online program with multiple plausibility and completeness checks. Participating hospitals received extended annual audit reports in which results were compared across institutions. More than 200 hospitals are currently participating in this registry, providing about 10,000 patients 
per year. The Trauma Registry is organized by the DGU. Due to the anonymity of data collection and the fact that the primary purpose of the registry is quality control, patient consent was not necessary.

For the present analysis, 1,535 patients with early CPR were included. The inclusion criteria were as follows: primarily admission from the pre-hospital site of injury; Injury Severity Score (ISS) of nine points or more; admission to a hospital in Germany; available data about pre-hospital and early in-hospital CPR attempts (performed/not performed); year of injury from 1993 to 2009. Of included patients, 814 received pre-hospital CPR, while 989 patients experienced cardiac arrest during the early in-hospital phase before ICU admission, and 268 patients had both pre-hospital and in-hospital CPR attempts. A total of 25,366 patients from the TRDGU with the same inclusion criteria, but without any CPR attempts, served as a 'trauma control group' (group E).

Patients from the TR-DGU were divided into the following three groups:

- group $\mathrm{A}_{\mathrm{TR}-\mathrm{DGU}}$ : pre-hospital CPR and ATH $(n=$ 814)

- group D: trauma control group without any CPR ( $n$ $=25,366)$

Group $A_{\text {TR-DGU }}$ from the TR-DGU corresponds to group $A_{G R R}$ from the GRR, which lists patients who were admitted to a hospital with circulation after cardiac arrest.

The GRR represents all patients with any pre-hospital cardiac arrest at the participating centers who received CPR treatment by emergency medical doctors, independently of ROSC. TR-DGU represents only patients with severe trauma who reached hospital with spontaneous circulation. Due to data security and confidentiality, there is no information available about whether or not individual patients were included in both registries in parallel. As the GRR does not provide any information about the in-hospital treatment and outcome after cardiac arrest and the TR-DGU is limited to trauma patients who had spontaneous circulation at hospital admission but does not contain data of patients who died at the scene, we combined data from these two large national registries in this study to analyze the midterm outcome of CPR after traumatic cardiac arrest in Germany.

\section{Statistics}

Data are presented as means \pm standard deviation (SD) for continuous variables and as percentages for categorical variables. Due to the multiplicity of groups and variables, together with the large sample size, statistical tests were limited to a few specific conditions. Continuous variables were compared using the non-parametric $U$ test, while frequencies were compared using the chisquared test. In the final combination of results, the relative frequencies from each data source were used to calculate relative percentages for patients with traumatic cardiac arrest in whom CPR was attempted (100\%). A $P$ value less than 0.05 was regarded as statistically significant. Two-tailed tests were applied. All of the analyses were performed with SPSS, version 18 (IBM Corporation, Somers, NY, USA).

\section{Results and discussion GRR}

Of 13,329 documented patients within the GRR database, $368(2.8 \%)$ patients were identified with cardiac arrest due to trauma. In 331 of these patients (89.9\%), cardiac arrest was present when the EMS personnel arrived at the scene, and in 37 patients $(10.1 \%)$, cardiac arrest occurred after arrival at the scene during medical treatment. ROSC could be achieved in 107 patients (29.1\%). A total of 101 patients (27.4\%) were transferred to a hospital, 95 of whom (25.8\%) had circulation on admission (group $\mathrm{A}_{\mathrm{GRR}}$; Table 1 and Figure 1), while six patients died during transfer. No ROSC at any time was observed in 261 patients (70.9\%). Patients who died at the scene or during transfer, and those who were admitted with ongoing CPR, were assigned to group B ( $n=273,74.2 \%$; Figure 1 and Table 1). Thus, approximately one of four patients with traumatic cardiac arrest in whom CPR was initiated reached hospital with spontaneous circulation.

In comparison with the group of patients in whom ROSC could not be achieved (group B), differences were observed with regard to the electrocardiography (ECG) findings (there were more patients with ventricular fibrillation who survived) and whether or not the event was observed (there were more survivors if it was observed).

Trauma patients who reached hospital with circulation after ROSC differed from the corresponding cardiac control patients who had ROSC (group C) in several aspects: trauma patients were younger, asystole was the predominant ECG finding $(P<0.001$, chi-squared test), and cardiac arrest occurred more frequently at a public place (e. g. workplace, street, public areas: $52.6 \%$ versus $25.2 \%$ ) than at home (27.4\% versus 58.6\%; $P<0.001$, chi-squared test). Patients with traumatic cardiac arrest had a mean age of 52.7 years ( \pm 22.8 years) in comparison with 67.8 years $( \pm 15.1$ years $)$ if there was a cardiac cause $(P<$ $0.001, U$ test). Bystander CPR was only performed in $16 \%$ of trauma patients compared with $21.6 \%$ of cardiac arrest patients with cardiac causes $(P=0.273$, chi-squared test).

\section{TR-DGU}

The overall hospital mortality rate for trauma cardiac arrest patients was 73\% $(n=593$ of 814; Table 2 group $\left.A_{\text {TR-DGU }}\right)$. Patients who were found without any 
Table 1 Patient characteristics, circumstances, and treatment of patients with cardiac arrest after trauma based on the German Resuscitation Registry

\begin{tabular}{|c|c|c|c|}
\hline & $\begin{array}{l}\text { A }_{\text {GRR }} \text { Hospital admission with } \\
\text { ROSC }\end{array}$ & $\begin{array}{l}\text { B Died at the scene or with } \\
\text { ongoing CPR }\end{array}$ & $\begin{array}{l}\text { C Hospital admission; cardiac } \\
\text { causes }\end{array}$ \\
\hline Patients (n) & 95 & 273 & 3673 \\
\hline Age (mean $\pm S D)$ & $52.7 \pm 22.8$ & $50.7 \pm 22.2$ & $67.0 \pm 15.1$ \\
\hline Aged over 60 years & $44.9 \%$ & $38.1 \%$ & $72.4 \%$ \\
\hline \multicolumn{4}{|l|}{ Age cohorts } \\
\hline $1-20$ years & $12.4 \%$ & $10.0 \%$ & $1.3 \%$ \\
\hline $21-40$ years & $16.9 \%$ & $24.5 \%$ & $3.4 \%$ \\
\hline 41-60 years & $25.8 \%$ & $29.0 \%$ & $24.4 \%$ \\
\hline $61-80$ years & $36.0 \%$ & $29.0 \%$ & $54.2 \%$ \\
\hline$>80$ years & $9.0 \%$ & $7.4 \%$ & $16.6 \%$ \\
\hline Male gender & $66.0 \%$ & $74.8 \%$ & $68.8 \%$ \\
\hline \multicolumn{4}{|l|}{ Scene of cardiac arrest } \\
\hline Home & $27.4 \%$ & $21.0 \%$ & $58.6 \%$ \\
\hline Nursing home & $2.1 \%$ & $2.2 \%$ & $2.9 \%$ \\
\hline Workplace & $3.2 \%$ & $4.9 \%$ & $2.6 \%$ \\
\hline Street & $32.6 \%$ & $46.1 \%$ & $9.9 \%$ \\
\hline Public place & $16.8 \%$ & $15.0 \%$ & $12.7 \%$ \\
\hline Medical institution & $1.1 \%$ & $1.9 \%$ & $5.1 \%$ \\
\hline Public event & $1.5 \%$ & $0.6 \%$ & \\
\hline Other & $14.7 \%$ & $7.5 \%$ & $7.7 \%$ \\
\hline \multicolumn{4}{|l|}{ ECG findings } \\
\hline Ventricular fibrillation & $16.3 \%$ & $4.4 \%$ & $52.0 \%$ \\
\hline PEA & $13.8 \%$ & $20.6 \%$ & $10.0 \%$ \\
\hline Asystole & $57.5 \%$ & $66.7 \%$ & $28.4 \%$ \\
\hline Other & $12.6 \%$ & $8.4 \%$ & $9.6 \%$ \\
\hline \multicolumn{4}{|l|}{ Cardiac arrest witnessed } \\
\hline No & $33.7 \%$ & $45.1 \%$ & $25.4 \%$ \\
\hline By lay people & $50.5 \%$ & $46.9 \%$ & $59.3 \%$ \\
\hline By EMS & $15.8 \%$ & $8.1 \%$ & $15.3 \%$ \\
\hline Bystander CPR & $16.0 \%$ & $13.2 \%$ & $21.6 \%$ \\
\hline Use of defibrillator & $31.6 \%$ & $26.4 \%$ & $70.1 \%$ \\
\hline \multicolumn{4}{|l|}{ Fluid resuscitation ( $\mathrm{mL}$; mean $\pm \mathrm{SD}$ ) } \\
\hline Total volume & $1194 \pm 1020$ & $890 \pm 1092$ & $577 \pm-423$ \\
\hline Crystalloids & $837 \pm 712$ & $585 \pm 628$ & $549 \pm 395$ \\
\hline Colloids & $319 \pm 486$ & $300 \pm 562$ & $25.8 \pm 117$ \\
\hline Hyperoncotic solutions & $46.9 \pm 111$ & $48.6 \pm 107$ & $11.4 \pm 50.2$ \\
\hline \multicolumn{4}{|l|}{ Time intervals (min; mean \pm SD) } \\
\hline Time from call to EMS arrival & $9.0 \pm 6.4$ & $8.3 \pm 5.0$ & $7.8 \pm 5.3$ \\
\hline $\begin{array}{l}\text { Time from accident to hospital } \\
\text { admission }\end{array}$ & $55.1 \pm 15.5$ & $65.1 \pm 68.0$ & $56.7 \pm 21.9$ \\
\hline
\end{tabular}

Group $A_{G R R}$ had ROSC at hospital admission, while group B did not have any ROSC or died at the scene. The cardiac control group, group C, had cardiac causes for cardiac arrest and reached hospital with ROSC. CPR, cardiopulmonary resuscitation; ECG, electrocardiography; EMS, emergency medical service; PEA, pulseless electrical activity; ROSC, return of spontaneous circulation; SD, standard deviation.

circulation at the initial pre-hospital assessment had an even poorer outcome $(n=279$; mortality rate $84 \%)$, whereas the initial presence of blood pressure was more beneficial ( $n=279$; mortality rate $64 \%$; Figure 2$)$.

Approximately one of three patients $(n=268 ; 33 \%)$ required additional CPR during initial treatment after hospital admission. These patients had a poorer outcome (mortality rate $87 \%$ ) than those who did not require any additional in-hospital CPR attempts (mortality rate $66 \%$; Figure 2 ).

Patients who received pre-hospital and in-hospital CPR and in whom blood pressure was not detectable initially had the poorest outcome $(n=83$; mortality rate 93\%). 


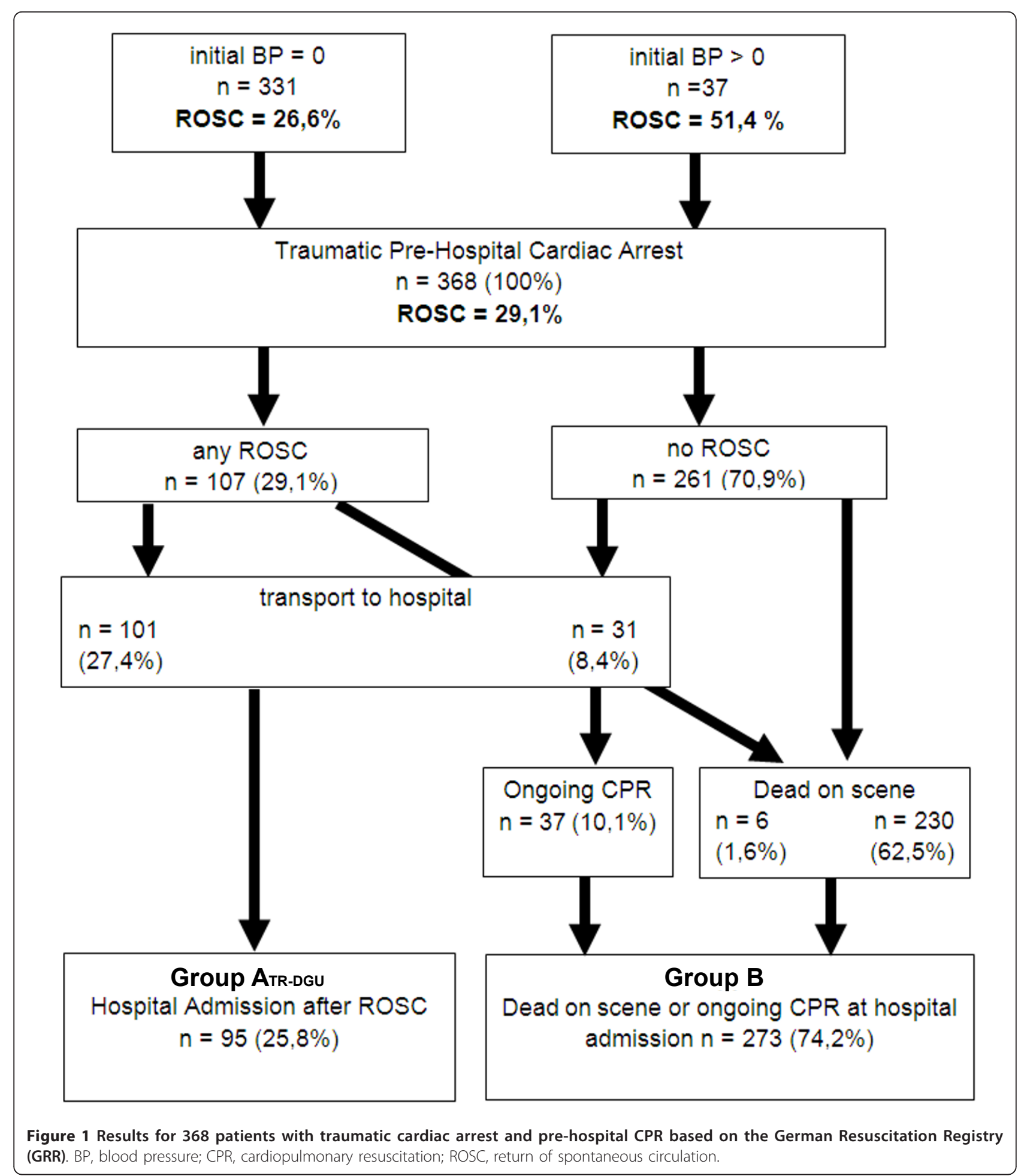

Trauma patients who received CPR had much more severe injuries, had more frequently head injuries, were more often in a state of shock, and underwent considerably more preclinical interventions such as catecholamine administration, endotracheal intubation, chest drainage, and volume substitution (Table 2).

Patients who needed in-hospital CPR received much larger amounts of blood transfusions than those with 
Table 2 Characteristics, treatment, and outcome of patients with severe trauma and cardiac arrest based on the Trauma Registry

\begin{tabular}{|c|c|c|}
\hline & $\mathrm{A}_{\text {TR-DGU }}$ Pre-hospital resuscitation & DNo resuscitation \\
\hline Patients (n) & 814 & 25,366 \\
\hline Age & $44.1 \pm 21.8$ & $42.2 \pm 20.6$ \\
\hline Aged $>60$ years & $28.3 \%$ & $22.4 \%$ \\
\hline Male gender & $72.2 \%$ & $72.9 \%$ \\
\hline Injury Severity Score & $39.9 \pm 19.7$ & $24.0 \pm 12.5$ \\
\hline Head injury (AIS $\geq 3$ ) & $74.6 \%$ & $47.5 \%$ \\
\hline Penetrating trauma & $6.4 \%$ & $4.7 \%$ \\
\hline Suicide (suspected) & $7.6 \%$ & $5.8 \%$ \\
\hline \multicolumn{3}{|l|}{ Mechanism of injury } \\
\hline Traffic & $60.9 \%$ & $62.9 \%$ \\
\hline High fall (> $3 \mathrm{~m}$ ) & $13.4 \%$ & $16.7 \%$ \\
\hline Initial blood pressure (mmHg) & $56 \pm 56$ & $121 \pm 31$ \\
\hline Shock $(B P \leq 90$ mmHg $)$ & $72.3 \%$ & $17.3 \%$ \\
\hline Cardiac arrest on arrival $(\mathrm{BP}=0 \mathrm{mmHg})$ & $41.5 \%$ & $0 \%$ \\
\hline Heart rate (beats/min) & $65 \pm 55$ & $95 \pm 21$ \\
\hline Endotracheal intubation & $97.7 \%$ & $53.8 \%$ \\
\hline Chest drain & $17.1 \%$ & $5.9 \%$ \\
\hline Catecholamines & $77.5 \%$ & $5.2 \%$ \\
\hline Volume administration & $93.7 \%$ & $92.3 \%$ \\
\hline Volume (total, mL) & $1886 \pm 1382$ & $1372 \pm 1056$ \\
\hline Crystalloids $(\mathrm{mL}) *$ & $1306 \pm 901$ & $1061 \pm 697$ \\
\hline Colloids $(\mathrm{mL}) *$ & $971 \pm 688$ & $786 \pm 516$ \\
\hline Hyperoncotic solutions $(\mathrm{mL}) *$ & $347 \pm 222$ & $328 \pm 238$ \\
\hline Time at scene (arrival to departure) & $34.6 \pm 17.1$ & $32.6 \pm 19.2$ \\
\hline Time from accident to hospital admission & $66.2 \pm 30.8$ & $69.7 \pm 36.4$ \\
\hline Transportation by helicopter & $38.1 \%$ & $40.1 \%$ \\
\hline Blood pressure $(\mathrm{mmHg})$ & $96 \pm 43$ & $125 \pm 29$ \\
\hline Shock (BP $\leq 90$ mmHg) & $44.7 \%$ & $11.6 \%$ \\
\hline Heart rate (beats/min) & $98 \pm 34$ & $90 \pm 20$ \\
\hline Blood transfusion & $44.7 \%$ & $27.6 \%$ \\
\hline Mass transfusion & $15.4 \%$ & $7.1 \%$ \\
\hline Cardiopulmonary resuscitation & $36.1 \%$ & $0 \%$ \\
\hline Emergency surgery & $14.5 \%$ & $6.3 \%$ \\
\hline Any surgery & $57.7 \%$ & $80.5 \%$ \\
\hline 24-hour mortality & $51.4 \%$ & $5.5 \%$ \\
\hline Hospital mortality & $72.9 \%$ & $12.5 \%$ \\
\hline Length of hospital stay in survivors (days; mean \pm SD) & $33.4 \pm 30.6$ & $29.1 \pm 27.8$ \\
\hline Length of hospital stay in non-survivors (days; mean \pm SD) & $3.9 \pm 8.9$ & $8.4 \pm 15.4$ \\
\hline \multicolumn{3}{|l|}{ GOS ** } \\
\hline Good recovery & $8.8 \%$ & $46.2 \%$ \\
\hline Minor limitations & $6.5 \%$ & $26.6 \%$ \\
\hline Severe limitations & $5.9 \%$ & $11.7 \%$ \\
\hline PVS & $4.9 \%$ & $2.4 \%$ \\
\hline Discharged at home & $6.9 \%$ & $38.6 \%$ \\
\hline Discharged at home among survivors & $24.3 \%$ & $44.1 \%$ \\
\hline
\end{tabular}

The trauma control group had no cardiac arrest until ICU admission.

AIS, Abbreviated Injury Scale; BP, blood pressure; GOS, Glasgow Outcome Scale; PVS, persistent vegetative state; SD, standard deviation. * If this type of volume was administered. ** The GOS has only been available since 2002 , and percentages therefore do not add up to exactly $100 \%$ with hospital mortality. 


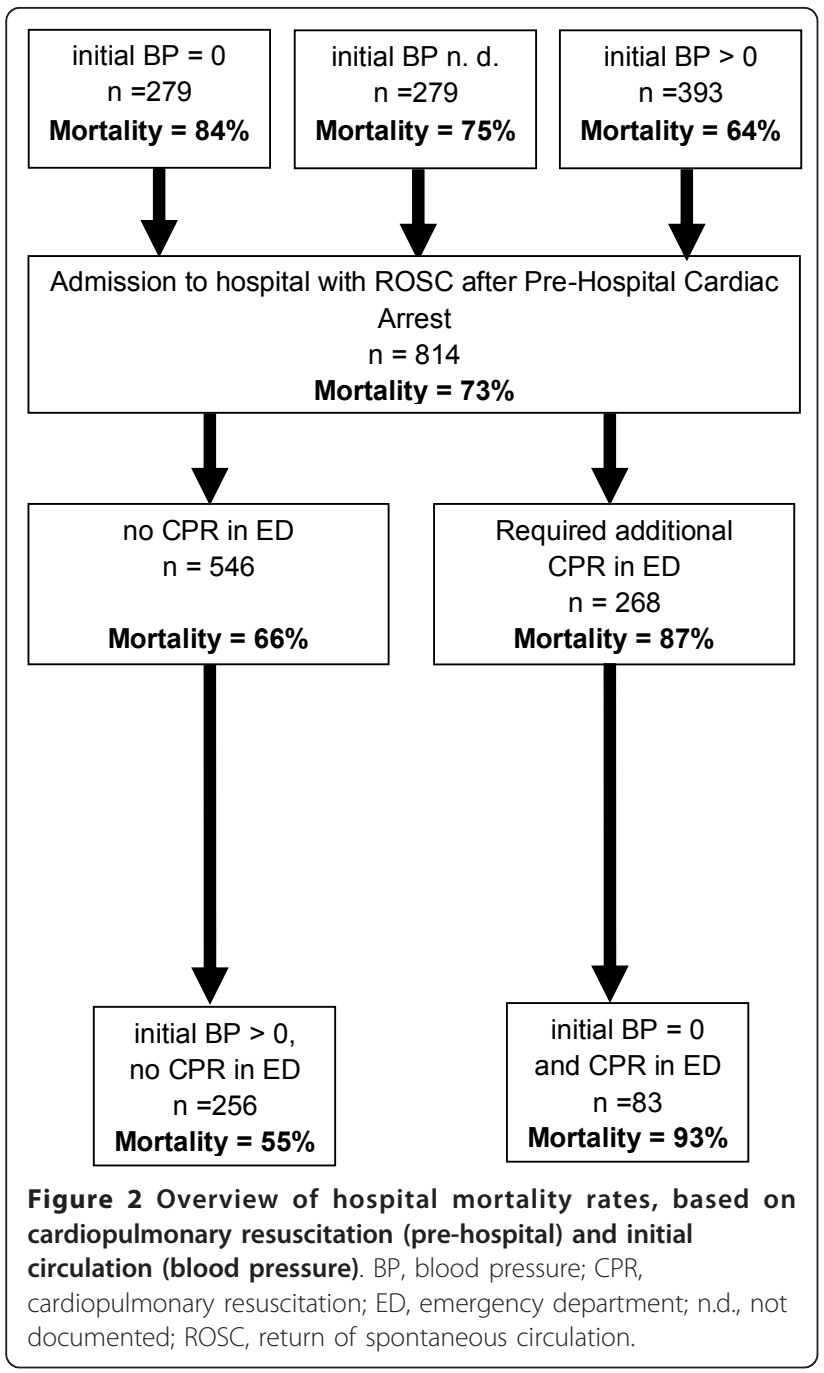

pre-hospital CPR, and they also required emergency surgical interventions much more often.

Patients who were discharged alive after pre-hospital CPR had various conditions: only $24 \%$ of survivors were able to be discharged at home, while the remaining patients were transferred to a secondary hospital or to rehabilitation clinics (Table 2). Persistent vegetative state (PVS) was observed in $4.9 \%$ of patients.

Figure 3 summarizes the results from both registries, with primary outcome calculated for an arbitrary group of trauma patients with cardiac arrest in whom CPR was initiated (defined as 100\%). ROSC was achieved in $29 \%$. Excluding patients who subsequently died pre-hospital or who had ongoing CPR on admission (3\%), 26\% of patients were admitted to hospital with spontaneous circulation. About half of these patients died within 24 hours, resulting in $13 \%$ survivors beyond 24 hours. Only $7 \%$ of the patients survived until hospital discharge.

The rate of cardiac arrest due to traumatic causes was $3 \%$ within the GRR comparable with rates reported internationally [12]. A direct comparison to the Trauma Registry is reasonably difficult due to differing inclusion and exclusion criteria in these two registries. However, data derived from these two registries may reflect the extent to which a good neurological outcome may be possible even in this group of cardiac arrest patients with a very poor prognosis.

Analysis from the GRR database revealed that preclinical CPR attempts resulted in a rate of $25 \%$ trauma patients with spontaneous circulation at hospital admission. However, follow up within the TR-DGU showed that hospital discharge rate is only $7 \%$, with 1 of 50 patients being able to be discharged with a good neurological outcome. These results are much worse compared with patients with cardiac etiology that have been reported previously $[13,14]$. In a review covering a 20year period in Sweden, Engdahl et al. reported similar low rates for ROSC and hospital admission in trauma patients with cardiac arrest [15]. Despite the poor outcome rates in our study, however, we strongly suggest that pre-hospital CPR attempts should not be withheld in patients with cardiac arrest due to trauma [16,17], as one patient out of 50 young adult patients can be discharged with good neurological outcome.

In addition, David et al. demonstrated in a study conducted in France, that aggressive and intensive therapy in these patients may be worthwhile [18]. The authors reported a ROSC rate of $34 \%$ and a hospital admission rate of $30 \%$.

These results also support our thesis that active CPR attempts after pre-hospital cardiac arrest may be as important in trauma patients as in medical patients, in particular if senior physicians are involved in patient's care [18]. Pickens et al. showed a discharge rate of 7.6\% in patients with trauma-related cardiac arrest, and further criticized recommendations that suggest not to perform CPR attempts in trauma patients [19]. These results deserve even more attention because the Seattle emergency service was a paramedic system that did not include emergency physicians.

The EMS described in the present study includes prehospital emergency physicians working together with the emergency service staff. This system further allows invasive interventions at the pre-clinical scene or during transport, such as chest drain insertion and endotracheal intubation, which are suggested to have positive effects on initial survival in trauma patients [20]. The present study identified differences in volume substitution therapy between trauma and cardiac patients, despite the fact that there were no significant differences either regarding the time at which care was provided at the scene, the arrival time of the emergency services, or bystander resuscitation attempts. Nevertheless, pre- and inhospital treatment should be considered as fast as 


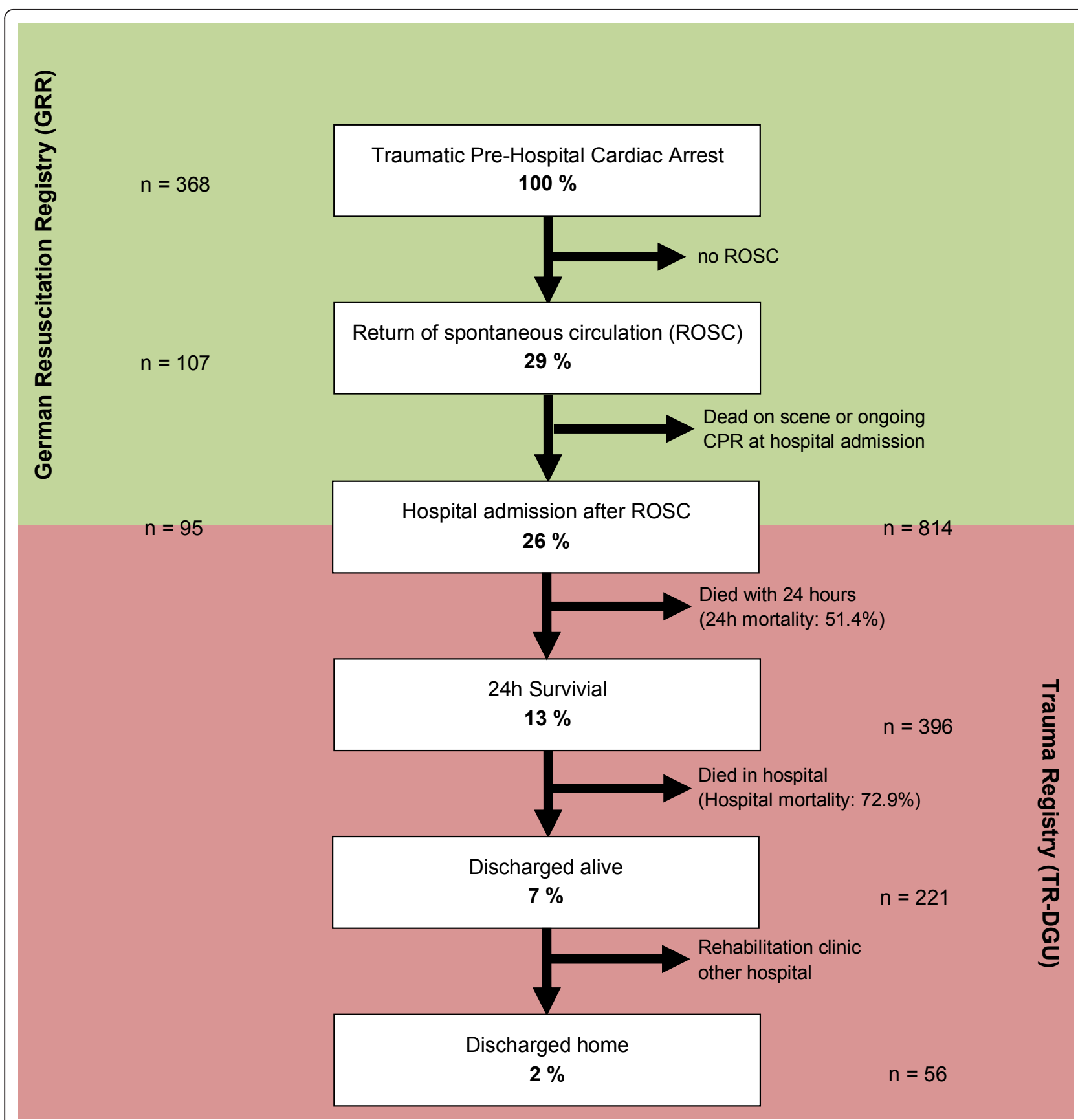

Figure 3 Summary of the results from the German Resuscitation Registry (GRR) and the Trauma Registry of the German Society for Trauma Surgery (TR-DGU) for patients with traumatic cardiac arrest in whom CPR was started (defined as 100\%). CPR, cardiopulmonary resuscitation; ROSC, return of spontaneous circulation.

possible. As some of the early deaths following injury are due to truncal hemorrhage, fast pre-hospital and inhospital treatment should also be recommended. There may be differences in blunt or penetration trauma. Nevertheless, reversible causes of cardiac arrest should be solved as soon as possible, following the international guidelines for resuscitation.
In the study conducted by Engdahl et al. in Göteborg, significant differences were also observed with respect to patient age, location of the event, and initial ECG [15]. Trauma-related cardiac arrest happens more often in much younger patients. In the present study, trauma patients were 15 years younger compared with patients with cardiac causes, and the proportion of patients aged 
over 60 years was $45 \%$ compared with $72 \%$ younger than 60 years. This difference in age was also found by David et al. [18]. The location of cardiac arrest also differed. More than $50 \%$ of all trauma-related cardiac arrest occurred in public places, suggesting that these patients were physically active until the onset of the cardiac arrest.

\section{Limitations}

On the basis of the requirements and definitions given in the Utstein-type protocol, most publications on CPR exclude cardiac arrest patients with non-cardiac causes. This substantially reduces the number for comparable publications.

Utstein recommended different end-points for describing the success of resuscitation after cardiac arrest. As the GRR does not focus on outcome following hospital admission, we stopped analysis at the time of hospital admission in the present study, but used data from the TR-DGU database for in-hospital follow up. The addition of further demographic variables, patient-related factors such as pre-existing diseases, and laboratory variables may lead to further improvements in the outcome. However, these variables were not recorded and therefore could not be included in the analysis.

In Germany, the EMS are staffed by physicians from several disciplines (mainly anesthesia, surgery, and internal medicine) who have additional training in emergency medicine. This structure allows more pre-clinical invasive technical interventions and the administration of drugs. It further allows the option of stopping any resuscitation attempts at the scene by declaring the cardiac arrest victim as dead. In this respect, the German system, however, does not allow comparisons with the corresponding results of paramedic-based EMS in terms of therapy or outcome.

Finally, documentation of patients within the TR-DGU was stopped when the patient was discharged from the acute-care hospital. It would be extremely valuable to have further follow-up data of these patients, but this is not allowed currently due to the anonymity of data collection.

\section{Conclusions}

In contrast to some trauma management programs [4] suggesting that patients with cardiac arrest caused by severe trauma may not have any chance of survival, our present study encourages CPR attempts in cardiac arrest patients following trauma. In the individual situation, the decision on whether to start resuscitation or not should be made liberally using comparable criteria as for cardiac patients. This is more important, because trauma patients are usually much younger than cardiac patients. However, this does not mean that patients who have injuries that are obviously not compatible with any chance of survival should undergo any resuscitation attempts. In this respect, trauma management programs that contains a more liberal algorithm supporting resuscitation attempts [21] should be encouraged.

\section{Key messages}

- Cardiac arrest caused by severe trauma is a rare situation

- Long-term survival with good neurological recovery is reported in up to $2 \%$ of patients

- Starting CPR may be worthwhile in patients with cardiac arrest following trauma

- Trauma management programs that undervalue CPR after trauma should be discussed critically

\section{Abbreviations}

ATH: admission to hospital; CPR: cardiopulmonary resuscitation; DGAl: Deutsche Gesellschaft für Anästhesiologie und Intensivmedizin, (German Society of Anaesthesiology and Intensive Care Medicine); DGU: Deutsche Gesellschaft für Unfallchirurgie (German Society for Trauma Surgery); ECG:

electrocardiography; EMS: emergency medical services; GRR: German Resuscitation Registry; ISS: Injury Severity Score; PVS: persistent vegetative state; ROSC: return of spontaneous circulation; SD: standard deviation; TRDGU: Trauma Registry of the German Society for Trauma Surgery.

\section{Acknowledgements}

The authors are indebted to all active participants of the GRR and the TR DGU who registered patients. Further, the authors would like to thank all professionals involved in pre-hospital emergency medical care and intensive care of the emergency physician-staffed emergency medical systems.

\section{Author details}

${ }^{1}$ Department of Anaesthesiology and Intensive Care Medicine, University Hospital Schleswig-Holstein, Campus Kiel, Schwanenweg 21, Kiel, 24105, Germany. ${ }^{2}$ Department of Anaesthesiology and Intensive Care Medicine, University Hospital Schleswig-Holstein, Campus Lübeck, Ratzeburger Allee 160, Lübeck, 23538, Germany. ${ }^{3}$ Department of Anaesthesiology and Intensive Care, Klinikum am Eichert,Eichertstraße 3, Göppingen, 73035, Germany.

${ }^{4}$ Department of Orthopedic and Trauma Surgery, Cologne Merheim Medical Center, Ostmerheimerstr. 200, Cologne, 51109, Germany. ${ }^{5}$ Institute for Research in Operative Medicine, Faculty of Health, University of Witten/ Herdecke, Alfred-Herrhausen-Straße 50, Witten, 58448, Germany.

\section{Authors' contributions}

JTG, PM and JW made substantial contributions to conception and design, and drafted the manuscript. SS and RL provided statistical support. MF conceived of the study, and participated in its design and coordination and helped to draft the manuscript. BB was involved in the internal reviewing process. TP and AW contributed data to the TR-DGU and helped to revise the manuscript. All authors read and approved the manuscript.

\section{Competing interests}

JTG, JW and MF are members of the steering committee of the German Resuscitation Registry. SS is an associated medical student working in the German Resuscitation Registry. TP and RL are members of the steering committee of the Trauma Register-DGU. All authors declare that there are no competing interests.

Received: 12 August 2011 Revised: 5 November 2011

Accepted: 22 November 2011 Published: 22 November 2011

\section{References}

1. Gräsner JT, Meybohm P, Fischer M, Bein B, Wnent J, Franz R, Zander J, Lemke H, Bahr J, Jantzen T, Messelken M, Dorges V, Böttiger BW, Scholz J: A 
national resuscitation registry of out-of-hospital cardiac arrest in Germany-a pilot study. Resuscitation 2009, 80:199-203.

2. Bouillon B, Walther T, Kramer M, Neugebauer E: Trauma and circulatory arrest. 224 preclinical resuscitations in Cologne in 1987-1990. Anaesthesist 1994, 43:786-790.

3. Huber-Wagner S, Lefering R, Qvick M, Kay MV, Paffrath T, Mutschler W, Kanz KG: Outcome in 757 severely injured patients with traumatic cardiorespiratory arrest. Resuscitation 2007, 75:276-285.

4. Campell J: Basic trauma life support for advanced providers. Persons Education; 5 2007.

5. Hopson LR, Hirsh E, Delgado J, Domeier RM, McSwain NE Jr, Krohmer J: Guidelines for withholding or termination of resuscitation in prehospital traumatic cardiopulmonary arrest: a joint position paper from the National Association of EMS Physicians Standards and Clinical Practice Committee and the American College of Surgeons Committee on Trauma. Prehosp Emerg Care 2003, 7:141-146.

6. Hopson LR, Hirsh E, Delgado J, Domeier RM, McSwain NE, Krohmer J: Guidelines for withholding or termination of resuscitation in prehospital traumatic cardiopulmonary arrest: joint position statement of the National Association of EMS Physicians and the American College of Surgeons Committee on Trauma. J Am Coll Surg 2003, 196:106-112.

7. Gräsner JT, Meybohm P, Lefering R, Wnent J, Bahr J, Messelken M, Jantzen T, Franz R, Scholz J, Schleppers A, Bottiger BW, Bein B, Fischer M: ROSC after cardiac arrest-the RACA score to predict outcome after outof-hospital cardiac arrest. Eur Heart J 2011, 32:1649-1656.

8. Grasner JT, Herlitz J, Koster RW, Rosell-Ortiz F, Stamatakis L, Bossaert L: Quality management in resuscitation - towards a European Cardiac Arrest Registry (EuReCa). Resuscitation 2011, 82:989-994.

9. Jacobs I, Nadkarni V, Bahr J, Berg RA, Billi JE, Bossaert L, Cassan P, Coovadia A, D'Este K, Finn J, Halperin H, Handley A, Herlitz J, Hickey R, Idris A, Kloeck W, Larkin GL, Mancini ME, Mason P, Mears G, Monsieurs K, Montgomery W, Morley P, Nichol G, Nolan J, Okada K, Perlman J, Shuster M, Steen PA, Sterz F, Tibballs J, Timerman S, Truitt T, Zideman D: Cardiac arrest and cardiopulmonary resuscitation outcome reports: update and simplification of the Utstein templates for resuscitation registries. A statement for healthcare professionals from a task force of the international liaison committee on resuscitation (American Heart Association, European Resuscitation Council, Australian Resuscitation Council, New Zealand Resuscitation Council, Heart and Stroke Foundation of Canada, InterAmerican Heart Foundation, Resuscitation Council of Southern Africa). Resuscitation 2004, 63:233-249.

10. Ringdal KG, Coats TJ, Lefering R, Di Bartolomeo S, Steen PA, Roise O, Handolin L, Lossius HM: The Utstein template for uniform reporting of data following major trauma: a joint revision by SCANTEM, TARN, DGUTR and RITG. Scand J Trauma Resusc Emerg Med 2008, 16:7.

11. Kuhne CA, Mand C, Sturm J, Lackner CK, Kunzel A, Siebert H, Ruchholtz S: The Trauma Network of the German Society for Trauma 2009. Unfallchirurg 2009, 112:878-884.

12. Lundy DJ, Ross SE, Schorr C, Jones AE, Trzeciak S: Outcomes of trauma victims with cardiac arrest who survive to intensive care unit Admission. J Trauma 2011, 71::E12-6.

13. Sasson C, Rogers MA, Dahl J, Kellermann AL: Predictors of survival from out-of-hospital cardiac arrest: a systematic review and meta-analysis. Circ Cardiovasc Qual Outcomes 2010, 3:63-81.

14. Olasveengen TM, Vik E, Kuzovlev A, Sunde K: Effect of implementation of new resuscitation guidelines on quality of cardiopulmonary resuscitation and survival. Resuscitation 2009, 80:407-411.

15. Engdahl J, Bang A, Karlson BW, Lindqvist J, Herlitz J: Characteristics and outcome among patients suffering from out of hospital cardiac arrest of non-cardiac aetiology. Resuscitation 2003, 57:33-41.

16. Battistella FD, Nugent W, Owings JT, Anderson JT: Field triage of the pulseless trauma patient. Arch Surg 1999, 134:742-745, discussion 745-746.

17. Luciano BA, Marcela GF, Cesar EP, de Godoy JM: Necessity of immediate cardiopulmonary resuscitation in trauma emergency. World I Emerg Surg 2010, 5:25.

18. David JS, Gueugniaud PY, Riou B, Pham E, Dubien PY, Goldstein P, Freysz M, Petit $P$ : Does the prognosis of cardiac arrest differ in trauma patients? Crit Care Med 2007, 35:2251-2255.

19. Pickens JJ, Copass MK, Bulger EM: Trauma patients receiving CPR: predictors of survival. J Trauma 2005, 58:951-958.
20. Clevenger FW, Yarbrough DR, Reines HD: Resuscitative thoracotomy: the effect of field time on outcome. J Trauma 1988, 28:441-445.

21. Lott C, Araujo R, Cassar MR, Di Bartolomeo S, Driscoll P, Esposito I, Gomes E, Goode P, Gwinnutt C, Huepfl M, Lippert F, Nardi G, Robinson D, Roessler M, Davis M, Thies KC: The European Trauma Course (ETC) and the team approach: past, present and future. Resuscitation 2009, 80:1192-1196.

doi:10.1186/cc10558

Cite this article as: Gräsner et al:: Cardiopulmonary resuscitation traumatic cardiac arrest - there are survivors. an analysis of two national emergency registries. Critical Care 2011 15:R276.

\section{Submit your next manuscript to BioMed Central and take full advantage of:}

- Convenient online submission

- Thorough peer review

- No space constraints or color figure charges

- Immediate publication on acceptance

- Inclusion in PubMed, CAS, Scopus and Google Scholar

- Research which is freely available for redistribution

Submit your manuscript at www.biomedcentral.com/submit
C Biomed Central 